\title{
Heterogeneous Photocatalysis Applied to Indoor Building Material: Towards an Improved Indoor Air Quality
}

\author{
Q.L. Yu ${ }^{a}$, M.M. Ballarib ${ }^{\mathrm{b}}$, H.J.H. Brouwers ${ }^{\mathrm{c}}$ \\ Department of Architecture, Building and Planning, Eindhoven University of Technology, P. O. Box \\ 513, 5600 MB Eindhoven, the Netherlands \\ aq.yu@bwk.tue.nl, bm.ballari@tue.nl, cjos.brouwers@tue.nl
}

Key words: heterogeneous photocatalytic oxidation, indoor air quality, kinetic model, indoor building material.

\begin{abstract}
In the present article, kinetics of the photocatalytic oxidation (PCO) of nitric oxide (NO, as a typical air pollutant) is addressed. An extended Langmuir-Hinshelwood reaction rate model is proposed to describe the PCO of NO under indoor air conditions. The derived model incorporates the influence of the indoor air conditions in the process of the PCO. The good agreement between the predictions from the model and experimental results indicates the validity of the proposed model.
\end{abstract}

\section{Introduction}

Indoor air quality (IAQ) is receiving more and more attention due to the very important role it plays on human being. Nitrogen oxides $\left(\mathrm{NO}\right.$ and $\mathrm{NO}_{2}$ ) and Volatile Organic Compounds (VOCs), as typical inorganic and organic indoor air pollutants, can be emitted from many sources such as cooking, tobacco smoke, furniture, and building materials. These indoor pollutants can cause serious health problems like drowsiness, headache, sore throat, etc. Therefore, it is of vital importance to remove them in order to promise a desired indoor air quality.

Heterogeneous photocatalytic oxidation has proven to be an effective technology for water or air purification in outdoor conditions, and to date the PCO has been investigated intensively [1, 2]. Our previous research [3] already showed that PCO can also be applied for the indoor air quality improvement. A modified $\mathrm{TiO}_{2}$ was used as the photocatalyst, which was then coated onto a new developed indoor building material under a European project (I-SSB) [4]. The present study addresses the kinetics of the PCO of NO under indoor air conditions. The objective is to propose a simplified kinetic model to describe the effect of indoor air conditions on the PCO behavior. An extended Langmuir-Hinshelwood (L-H) model is proposed to describe the photocatalytic NO reaction rate under different experimental conditions. The good agreement between the model predictions with the experimental results indicates the validity of the proposed model.

\section{Materials and experimental}

The PCO technology was applied into the development of a novel gypsum based indoor building material with the improved indoor air quality function in the present study. Detailed information about the applied photocatalyst and its dosage was presented in [3]. A PCO set-up was employed in the present study for the indoor air decontamination assessment according to the standard ISO 22197-1:2007 [5], as shown in Fig. 1.

NO was chosen as model pollutant in the first stage of our study. All the experiments were carried out at room temperature to simulate the real indoor air since this new material is used directly at ambient conditions. Besides the tests carried out under a standard test condition deployed following ISO 22197-1:2007 [5] as a reference, a variety of different test conditions were employed to study their effect, and the main parameters are listed in Table 1. 


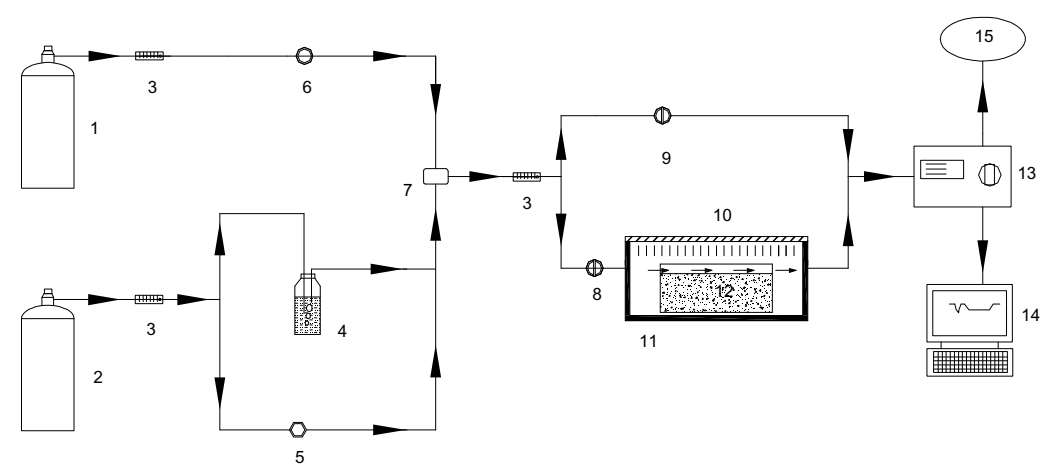

Fig. 1. Schematic diagram of photocatalytic degradation setup. 1. NO gas supply. 2. Synthetic air. 3. Flow rate meter. 4. Humidifier. 5. Humidity controller. 6. NO concentration controller. 7. Temperature and relative humidity sensor. 8. Valve. 9. Valve. 10. Light source. 11. Reaction chamber. 12. Reactor. 13. $\mathrm{NO}_{\mathrm{x}}$ analyzer. 14. Computer. 15. Vent.

Table 1. Employed experimental conditions.

\begin{tabular}{|c|c|c|}
\hline Parameter & $\begin{array}{c}\text { Standard } \\
\text { conditions }\end{array}$ & Varying conditions \\
\hline Reactor Height $\mathrm{H}[\mathrm{mm}]$ & 3 & $2-9$ \\
\hline Initial NO concentration $\mathrm{C}_{\mathrm{NO}, \text { in }}[\mathrm{ppm}]$ & 0.5 & $0.1-1.0$ \\
\hline Volumetric flow rate $\mathrm{Q}\left[\mathrm{dm}^{3} \mathrm{~min}^{-1}\right]$ & 3 & $1-5$ \\
\hline Relative humidity $\mathrm{RH} \times 100[\%]$ & 50 & $10-70$ \\
\hline Irradiance $\mathrm{E}\left[\mathrm{Wm}^{-2}\right]$ & 10 & $1-13$ \\
\hline Photocatalyst content $\mathrm{D}_{\mathrm{TiO} 2}\left[\mathrm{gg}^{-1}\right]$ & 0.5 & $0.02-0.5$ \\
\hline
\end{tabular}

\section{Proposal of an extended L-H model}

The Langmuir-Hinshelwood model was employed to describe the NO conversion rate in gas-solid phase for heterogeneous photocatalysis in our previous study [6]:

$$
\mathrm{r}=\frac{\mathrm{kKC}_{\mathrm{NO}}}{1+\mathrm{KC}_{\mathrm{NO}}} \text {. }
$$

Where $\mathrm{r}$ is the reaction rate $\left[\mathrm{mol} \mathrm{dm} \mathrm{min}^{-1}\right], \mathrm{k}$ is the reaction rate constant $\left[\mathrm{mol} \mathrm{dm}^{-2} \mathrm{~min}^{-1}\right], \mathrm{K}$ is

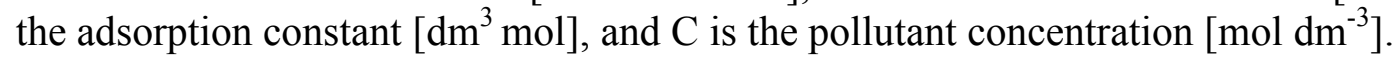

Along the longitudinal direction of the reactor, the NO mass balance reads:

$$
\mathrm{v}_{\text {air }} \frac{\mathrm{dC}_{\mathrm{NO}}}{\mathrm{dx}}=-\mathrm{a}_{\mathrm{v}} \mathrm{r}_{\mathrm{NO}}=-\mathrm{a}_{\mathrm{v}} \frac{\mathrm{kKC}_{\mathrm{NO}}}{1+\mathrm{KC}_{\mathrm{NO}}} \text {. }
$$

Where $v_{\text {air }}$ is the linear air velocity $\left[\mathrm{dm} \mathrm{min}^{-1}\right]$, and $\mathrm{a}_{\mathrm{v}}$ is the active surface area per unit of reactor volume related with the dosage of the photocatalyst $\left(\mathrm{a}_{\mathrm{v}}=\mathrm{D}_{\mathrm{TiO}_{2}} / \mathrm{H}\left[\mathrm{dm}^{-1}\right]\right.$, here $\mathrm{D}_{\mathrm{TiO} 2}$ is the dosage of the photocatalyst (\%)).

A linear model was derived from Eq. (2) and validated to describe the reaction rate of PCO and test conditions like initial concentration, flow rate and reactor size were taken into account [6].

However, as presented in $[2,3]$, other experimental conditions like irradiance and relative humidity influence significantly the PCO efficiency as well. Hunger et al. [2] highlighted the difficulty of predicting the performance of a photocatalytic cementitious system due to a large number of variables involved. Nevertheless, they reported that, when all the other experimental conditions remain as standard [5], the reaction rate constant increases as the increase of the irradiance, according to 


$$
\mathrm{k}=\mathrm{b}_{1}\left(-1+\sqrt{1+\mathrm{b}_{2} \mathrm{E}}\right) \text {. }
$$

On the other hand, the adsorption constant can be considered independent on the irradiance [2]. Regarding the effect of relative humidity (RH) over the NO PCO, Hunger et al. [2] proposed that the reaction rate constant has a power relation while the adsorption constant has a polynomial relation with the $\mathrm{RH}$ with all the other experimental conditions remaining constant [5]:

$$
\begin{aligned}
& \mathrm{k}=\mathrm{b}_{3} \mathrm{RH}^{\mathrm{b}_{4}} . \\
& \mathrm{K}=\mathrm{b}_{5} \mathrm{RH}^{2}+\mathrm{b}_{6} \mathrm{RH}+\mathrm{b}_{7} .
\end{aligned}
$$

Here in Eqs. (3) - (5), $b_{1}$ and $b_{2}$ are related parameters with irradiance, and $b_{3}-b_{7}$ are related parameters with relative humidity.

However, these relations introduced above were derived separately by only changing one experimental factor [2], which obviously could not represent the PCO performance under the real indoor air conditions. In the present study, we consider the given relations together assuming the two mentioned experimental factors vary simultaneously, therefore a new expression for the reaction rate constant related with irradiance and $\mathrm{RH}$ is derived:

$$
\mathrm{k}=\mathrm{b}_{8}\left(-1+\sqrt{1+\mathrm{b}_{2} \mathrm{E}}\right) \mathrm{RH}^{b_{4}} \text {. }
$$

Here in Eq. (6), $b_{8}$ is a relevant parameter.

Replacing the given expressions by Eqs. (5) and (6) for $\mathrm{k}$ and $\mathrm{K}$ respectively into Eq. (1) while considering the boundary condition $\mathrm{C}(\mathrm{x}=0)=\mathrm{C}_{\text {in }}$, Eq. (2) can be solved numerically applying the Euler method, and the $\mathrm{NO}$ concentration along the reactor is obtained:

$$
\mathrm{C}_{\mathrm{NO}, \mathrm{i}+1}=\frac{\left(\mathrm{x}_{\mathrm{i}+1}-\mathrm{x}_{\mathrm{i}}\right)}{\mathrm{v}_{\text {air }}} \frac{-\mathrm{a}_{\mathrm{v}}\left(\mathrm{b}_{8}\left(-1+\sqrt{1+\mathrm{b}_{2} \mathrm{E}}\right) \mathrm{RH}^{b_{4}}\right)\left(\mathrm{b}_{5} \mathrm{RH}^{2}+\mathrm{b}_{6} \mathrm{RH}+\mathrm{b}_{7}\right) \mathrm{C}_{\mathrm{NO}, \mathrm{i}}}{1+\left(\mathrm{b}_{5} \mathrm{RH}^{2}+\mathrm{b}_{6} \mathrm{RH}+\mathrm{b}_{7}\right) \mathrm{C}_{\mathrm{NO}, \mathrm{i}}}+
$$

\section{Optimization of the kinetic parameters}

The kinetic parameters in Eq. (7), here termed as the full model, are obtained by optimizing this equation employing the "solver" tool from Microsoft Excel and the experimental data from 39 PCO tests [3]. The results are shown in Table 2. The obtained value for the total percent root-meansquare error between the experimental data and the model predictions applying these optimized parameters is $7.35 \%$.

With the obtained parameters, the term $\left(1+\left(b_{5} \mathrm{RH}^{2}+\mathrm{b}_{6} \mathrm{RH}+\mathrm{b}_{7}\right) \mathrm{C}_{\mathrm{NO}, \mathrm{i}}\right)$ in the denominator of Eq. (7) was calculated showing that it can be equalled to unity; at the same time $\left(-1+\sqrt{1+b_{2} E}\right)$ tends to be $\sqrt{b_{2} E}$; and $b_{6} R H$ can be neglected from $\left(b_{5} R^{2}+b_{6} R H+b_{7}\right)$. Therefore, the expression of the NO concentration along the reactor is simplified to:

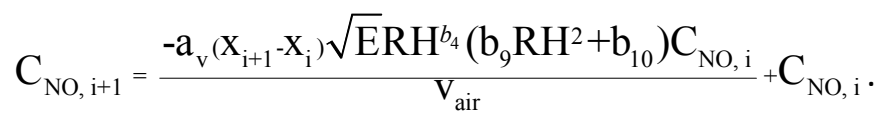

The kinetic parameters in the simplified model (Eq. (8)) then are determined again employing the "solver" tool from Microsoft Excel and the experimental data [3], obtaining the same total rootmean-square error of $7.35 \%$. The results are listed in Table 2. 
Table 2. Optimized kinetic parameters employing the Excel Solver tool.

\begin{tabular}{|c|c|c|}
\hline Proposed model & Parameter & Value \\
\hline \multirow{4}{*}{ Full } & $\mathrm{b}_{2}\left[\mathrm{~m}^{2} \mathrm{~W}^{-1}\right]$ & $2.24 \times 10^{2}$ \\
\cline { 2 - 3 } & $\mathrm{b}_{4}[--]$ & $1.11 \times 10^{-1}$ \\
\cline { 2 - 3 } & $\mathrm{b}_{5}\left[\mathrm{dm}^{3} \mathrm{~mol}^{-1}\right]$ & $2.92 \times 10^{0}$ \\
\cline { 2 - 3 } & $\mathrm{b}_{6}\left[\mathrm{dm}^{3} \mathrm{~mol}^{-1}\right]$ & $0.00 \times 10^{0}$ \\
\cline { 2 - 3 } & $\mathrm{b}_{7}\left[\mathrm{dm}^{3} \mathrm{~mol}^{-1}\right]$ & $5.02 \times 10^{-1}$ \\
\cline { 2 - 3 } & $\mathrm{b}_{8}\left[\mathrm{moldm}^{-2} \mathrm{~min}^{-1}\right]$ & $2.12 \times 10^{-2}$ \\
\hline \multirow{4}{*}{ Simplified } & $\mathrm{b}_{4}[--]$ & $1.11 \times 10^{-1}$ \\
\cline { 2 - 3 } & $\mathrm{b}_{9}\left[\mathrm{dm}^{2} \mathrm{~min}^{-1} \mathrm{~W}^{-0.5}\right]$ & $9.10 \times 10^{0}$ \\
\cline { 2 - 3 } & $\mathrm{b}_{10}\left[\mathrm{dm}^{2} \mathrm{~min}^{-1} \mathrm{~W}^{-0.5}\right]$ & $1.56 \times 10^{0}$ \\
\hline
\end{tabular}

\section{Validation of the derived model}

Fig. 2 shows the NO outlet concentration predicted by the simplified model. The good agreement between the predicted value and the experimental data indicates the validity of the model.

Fig. 3 shows the influence of the test conditions such as relative humidity, initial pollutant concentration, and irradiance on the PCO performance predicted from the simplified model versus the experimental data. Also they confirm that the model works effectively under these conditions.

Hunger et al. [2] reported that for small E, Eq. (3) tends to $b e b_{1} b_{2} E / 2$, while for large $E$ it tends to be $b_{1}\left(b_{2} E\right)^{0.5}$, which is in line with [7]. The reason is that in the first order regime the generated electron-hole pairs are consumed more rapidly by PCO reaction than by recombination, whereas in the second regime the recombination is dominant, which is confirmed by the present study.

$\mathrm{RH}$ has a complicated effect depending on the employed photocatalytic substrate as well as test conditions. For the PCO reaction, water is compulsory, but water also competes with other reactants for the adsorption sites of the photocatalyst, which decreases its depolluting performance. This is also confirmed by [2], who reported a quite different value of $b_{5}, b_{6}$, and $b_{7}$ for a concrete paving stone from the present study and found the NO conversions decreases when the RH increases.

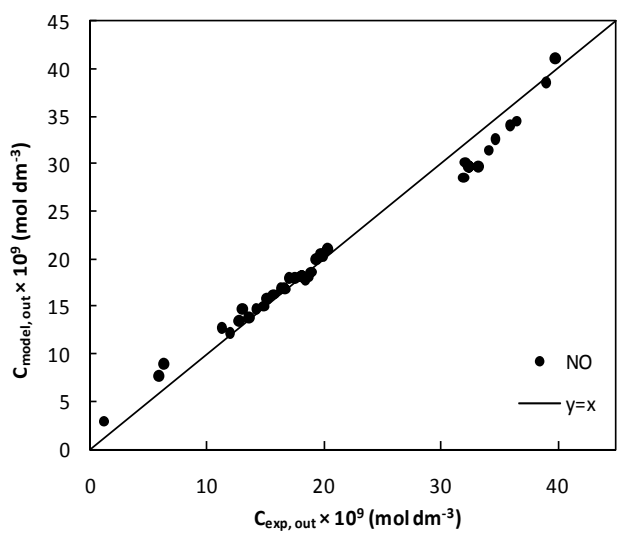

Fig. 2. Model predictions versus the test data. 


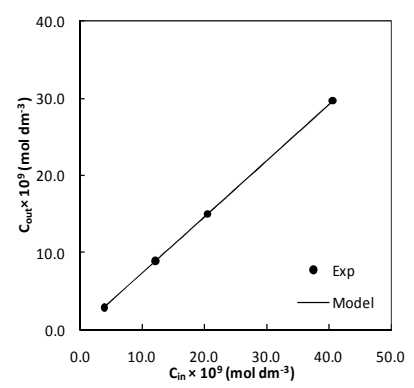

a

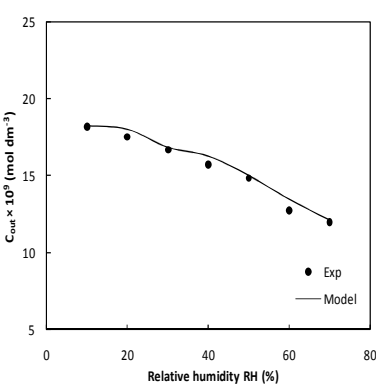

$\mathrm{b}$

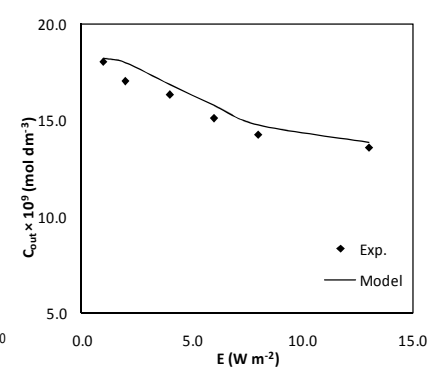

c

Fig. 3. Effect of test conditions. a: initial concentration; b: relative humidity; c: irradiance.

\section{Conclusions}

The present study addresses the reaction kinetics of the photocatalytic oxidation of NO under indoor air conditions. A novel indoor building material was developed with the function of indoor air quality improvement applying heterogeneous photocatalysis. Experiments were performed to degrade NO under different operating conditions. An extended Langmuir-Hinshelwood model was derived to describe the PCO under different conditions like irradiance and relative humidity. The good agreement between the predictions from the model and the experimental data shows this model works effectively under given conditions, however this also indicates the limitation of the derived L-H model. Furthermore, the present results provide a support to understand the indoor air quality applying PCO under real indoor air conditions.

\section{Acknowledgements}

The authors wish to express their gratitude to the European Commission (I-SSB Project, Proposal No.026661-2) for funding this research and the following sponsors of the research group: Bouwdienst Rijkswaterstaat, Graniet-Import Benelux, Kijlstra Betonmortel, Struyk Verwo, Insulinde, Enci, Provincie Overijssel, Rijkswaterstaat Directie Zeeland, A\&G maasvlakte, BTE, Alvon Bouwsystemen, V.d. Bosch Beton, Selor, Twee "R" Recycling, GMB, Schenk Concrete Consultancy, De Mobiele Fabriek, Creative Match, Intron, Geochem Research, Icopal, and BN International (chronological order of joining).

\section{References}

[1] A. Fujishima and K. Honda: Nature Vol. 238 (1972) p. 37.

[2] M. Hunger, G. Hüsken and H.J.H. Brouwers: Cem. Concr. Res. Vol. 40 (2010), p. 313.

[3] Q.L. Yu and H.J.H. Brouwers: Appl. Catal. B - Environ. Vol. 92 (2009), p. 454.

[4] EU Project, The Integrated Safe \& Smart Built Concept (I-SSB). http://www.issb-project.com/.

[5] ISO 22197-1:2007. Fine ceramics (advanced ceramics, advanced technical ceramics) - Test method for air purification performance of semiconducting photocatalytic materials - Part 1: Removal of nitric oxide; 2007.

[6] Q.L. Yu, M.M. Ballari and H.J.H. Brouwers: In Bittnar Z, Bartos PJM, Nemecek J, Smilauer V, Zeman J, editors. Proceedings the $3^{\text {rd }}$ international symposium on nanotechnology in construction. June 2009, Prague, Czech. Springer-Verlag Berlin Heidelberg, Germany; (2009): p. 389.

[7] J.M. Herrmann: Catal. Today Vol. 53 (1999), p. 115. 
Advances in Civil Engineering

doi:10.4028/www.scientific.net/AMR.255-260

Heterogeneous Photocatalysis Applied to Indoor Building Material: Towards an Improved Indoor Air Quality

doi:10.4028/www.scientific.net/AMR.255-260.2836 